\title{
An automatic multi-axis solar tracking system in Ramadi city: design and implementation
}

\author{
Mustafa Hamid Al-Jumaili ${ }^{1}$, Hussein M. Haglan ${ }^{2}$, Mohammed Kareem Mohammed ${ }^{3}$, \\ Qusay Hatem Eesee ${ }^{4}$ \\ ${ }^{1,3,4}$ Renewable Energy Research Center, University of Anbar, Iraq \\ ${ }^{2}$ Computer Center, University of Anbar, Iraq
}

\section{Article Info}

Article history:

Received Jan 7, 2020

Revised Mar 23, 2020

Accepted Apr 5, 2020

\section{Keywords:}

LDR

Multi-axis tracker

Panel efficiency

Solar panel

Solar tracker

\begin{abstract}
In this paper, a complete design and implementation of an automatic Multi-Axis solar tracking system has been introduced. The main purpose of this system is to track Sun location and gain the maximum energy output of the solar panels. The system is Multi-axis using microcontroller and photocells to control the direction of the penal, whereas the penal is facing the sun at all time of the day. The system is a combination of hardware and software parts that work concurrently to achieve a precise angular Sun tracking. A Base, Penal Frame, Super Jack Motors, high-efficiency Solar Panel, Arduino Uno microcontroller, Relays, Rechargeable battery, Light Dependent Resistor (LDR) have been used for the system's hardware part. These hardware parts need a high-level programming code, as a software part, to be embedded in the microcontroller to get an effective and precise solar tracking system. The results of the presented system were compared to a fixed direction system. The results show significant efficiency improvement of $24 \%$ over the static one. For a city like Ramadi, which has a high irradiance all over the year, it is very fruitful to use such tracking systems along with photovoltaic installation systems.
\end{abstract}

Copyright $\odot 2020$ Institute of Advanced Engineering and Science. All rights reserved.

Corresponding Author:

Mustafa Hamid Al-Jumaili,

Renewable Energy Research Center,

University Of Anbar, Ramadi, Anbar, Iraq.

Email: Mustafa.Hamid@uanbar.edu.iq

\section{INTRODUCTION}

Nowadays, solar electric is used in almost all over the world. This makes the solar energy source one of the most promising energy sources in the near future. Moving toward renewable energy is one of the goals of experts in the environment and engineering. Increasing the solar systems efficiency and improving their performance is a hot topic which attracted many researchers around the globe [1].

The Sun is one of the prime energy sources, which is considered as a fuel for many types of renewable systems. To replace the traditional energy source, it is required a renewable system that can be robust and reliable, which is in this time the photovoltaic (PV) system. PV system has the biggest share of the sustainable working systems in many countries and places. The main advantage of solar panels is that they can directly convert solar radiation into electrical power. Since the maximum efficiency of silicon solar cells is about $24.5 \%$, there is one way to enhance their performance, which is by increasing the intensity of falling light on the top of them [2]. Solar tracking systems are one of the most suitable and proven technologies to improve solar panels efficiency. The idea is the solar tracking system keeps the solar panel aligned with the position of the Sun. in recent days, solar tracking systems are highly utilized for two reasons: increasing the energy collected by solar panels and costly effective, which is far more cheaper than installing additional solar systems. 
Recent studies have shown that the process of directing solar panels using conventional methods at a fixed location (where the installation of solar panels was in the middle between east and west, and 30 degrees to the south direction) is not perfect [3]. It is therefore best to orient solar panels in one axis or two axes toward the sun in a manner that is proportional to the path of the sun in order to ensure the extraction of the greatest energy from the sun. Many researchers study and worked daily to develop and improve the efficiency of solar cells. But few research studies in the past years have worked on the design of an automated tracking system of solar energy integrated into solar panels [4-7], these efforts are made to ensure that the direction of the panels is always compatible with the circular path of the sun. Thus, the proportion of energy produced by solar panels increases from $30 \%$ to $60 \%$ better than the fixed system [8, 9]. However, from previous studies we conclude that there are many challenges affecting the production of solar energy, which must take into account in building the system of tracking the path of the sun: Solar light sensor, energy consumption to run the tracking engine, determination of the first location of the solar panel, reflection of scattered radiation from the sun to the surface of the earth due to clouds, dust and water that reduce the production capacity of solar cells. On the contrary, if these radiations are reflected on the solar panels, they will increase the total energy output of solar panels [10,11]. However, many algorithms have been developed in this area, but there is still no perfect solar tracking system that can be used in all regions on Earth surface because of the changing climatic conditions from one region to another. The most important of these conditions are the length of time remains the sun is bright in the day for each region and the kinetic path of the sun in that region $[12,13]$.

In this paper we have developed a Multi-Axis solar tracking system based on the climatic conditions at Ramadi city in Iraq. The design methodology of a microcontroller based simple and easily programmed automatic solar tracker is presented. A prototype of automatic solar tracker ensures feasibility of this design methodology.

\section{CLIMATE CONDITIONS OF RAMADI CITY}

Ramadi city is located in the west of Iraq with Latitude of 33.42 and Longitude of 43.31 as shown in Figure 1. It has a very high rate of average Sun hours of 11.32 Hours as explained in Table 1 and Figure 2, very high Sun index of 93-96 percent per season as in Table 2 and very low Sun hours lost as in Table 3 [14]. The availability of such a free source of energy (Sun Energy) makes the location of Ramadi City very suitable for renewable energy systems, especially solar farms. To increase the efficiency of the solar system in terms of getting the maximum energy output achievable, solar tracking system need to be used. In contrary to the traditional solar systems, solar trackers can improve the overall system efficiency and gain the maximum output of the solar panels.

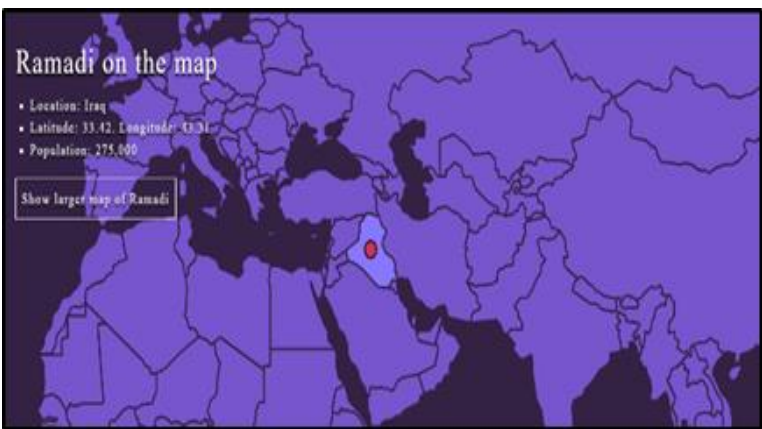

(a)

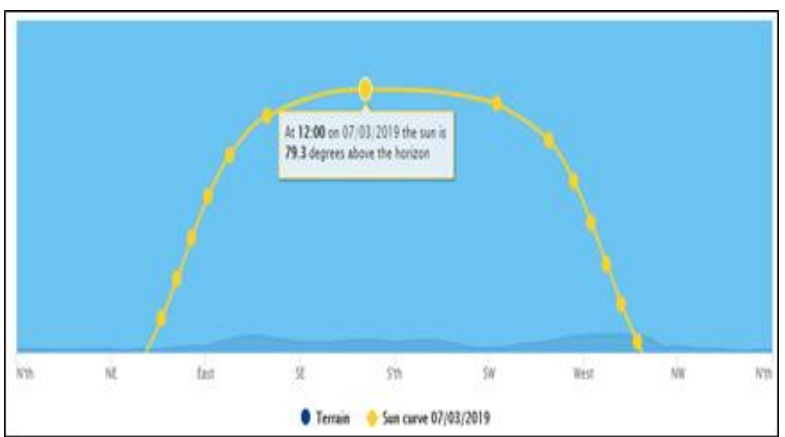

(b)

Figure 1. (a) Location of Ramadi City on the map, (b) Sun curve at Ramadi City on July $3^{\text {rd }}, 2019$

Table 2 and 3 shows the Sun indexes and the key Sun stats. An index value of 100 percent means that there is no terrain shading. If the index is 50 percent, the terrain blocks the sun half the time. The key stats show the most important sun facts for Ramadi, Iraq. By sun hours lost it means the number of hours that the sun is shaded by the terrain. 
Table 1. Daily Average Sun Time and Monthly Sun Hours in Ramadi City

\begin{tabular}{cccccc}
\hline Period & Total $(\%)$ & Morning $(\%)$ & Afternoon $(\%)$ & Sun hours & Daily average sun time \\
\hline Overall & 95 & 96 & 94 & 4211 & $11: 32$ \\
January & 93 & 91 & 95 & 295 & $9: 31$ \\
February & 94 & 92 & 95 & 288 & $10: 17$ \\
March & 95 & 96 & 94 & 351 & $11: 19$ \\
April & 95 & 98 & 93 & 371 & $13: 19$ \\
May & 96 & 99 & 93 & 413 & $13: 46$ \\
June & 96 & 98 & 94 & 413 & $13: 33$ \\
July & 96 & 99 & 94 & 420 & $12: 45$ \\
August & 95 & 98 & 93 & 395 & $11: 46$ \\
September & 95 & 97 & 93 & 353 & $9: 39$ \\
October & 94 & 94 & 94 & 330 & $9: 19$ \\
November & 93 & 92 & 95 & 292 & $9: 41$ \\
December & 93 & 91 & 95 & 289 & $12: 21$ \\
Winter & 93 & 91 & 95 & 872 & $13: 21$ \\
Spring & 95 & 98 & 93 & 1136 & $10: 43$ \\
Summer & 96 & 98 & 94 & 1228 & 975 \\
Autumn & 94 & 94 & 94 & & \\
\hline
\end{tabular}

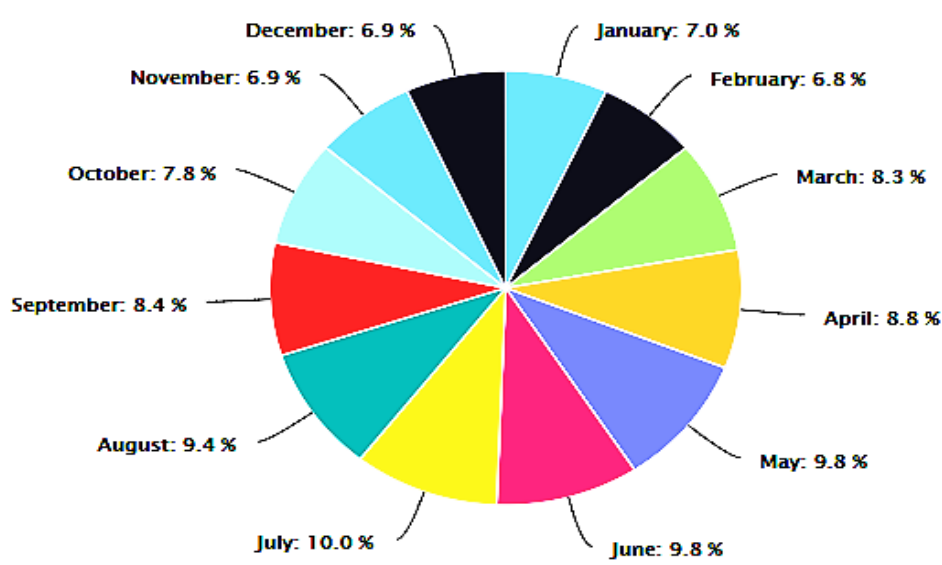

Figure 2. Monthly share of annual sun time given no clouds

Table 2. Sun indexes

\begin{tabular}{cc} 
Table 2. Sun indexes \\
\hline Total & $95 \%$ \\
Morning & $96 \%$ \\
Afternoon & $94 \%$ \\
Winter & $93 \%$ \\
Spring & $95 \%$ \\
Summer & $96 \%$ \\
Autumn & $94 \%$ \\
\hline
\end{tabular}

Table 3. Key sun stats

\begin{tabular}{cc}
\hline Latest sunset & $18: 52$ \\
Earliest sunrise & $5: 02$ \\
Latest sunrise & $7: 37$ \\
Earliest sunset & $16: 44$ \\
Average cloud cover & $38 \%$ \\
Average sun hours per day & $11: 32$ \\
Avg PM sun hrs lost & $0: 23$ \\
Avg AM sun hrs lost & $0: 15$ \\
\hline
\end{tabular}

\section{SOLAR TRACKER DESIGN}

Solar tracking systems are a hot topic and it has been an attractive subject for many researchers. Lately, the world becomes more depending on the renewable energy source. Since solar is one of the most sustainable energy sources in use. Solar tracking systems are enhancing the performance of this energy source [15-17]. It is very useful to have the solar system track the sun location as it moves across the sky in a daily routine. To have as much as we can of the solar irradiance during the day the panel needs to be in a perpendicular position with the sun location $[18,19]$. Here is the advantage of solar tracker appear. To reduce the lost irradiance many tracking systems have been proposed, yet the available systems are much costly as well as to the cost of the solar panel system. Cost is a key parameter in any system, an effective solution has been presented in this paper by reducing the cost and improving efficiency [20-22]. Four main components are used in this project: LDR Photoresistor, Arduino Microcontroller, Super Jack Motor, and a Solar Panel as shown in the block diagram Figure 3. 


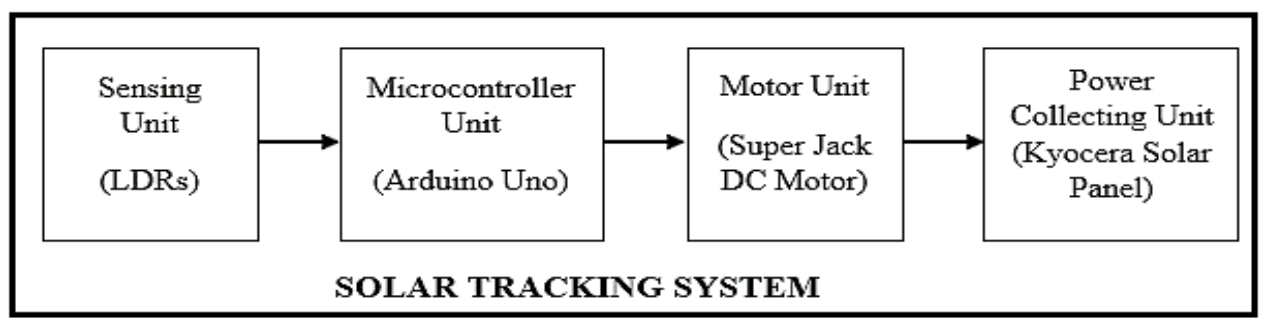

Figure 3. Block diagram of automatic solar tracking system

\section{SENSING UNIT}

In most solar tracking systems, there are several types of light sensors. Light Dependent Resistor (LDR) is one of these light sensors. Where the LDR sensor can be defined as a sensor to light that is coming from the sun along the day by receiving sunlight and giving a numerical value to the controller to direct the solar panels in a direction where the solar radiation has its maximum capacity [23-25]. Thus, LDR has a significant role in increasing the amount of solar energy extracted from solar panels. Four LDR-type sensors were used in this project, two for vertical movement and two for horizontal movement in order to increase efficiency in solar energy. The controller will receive four numerical values from the four LDR sensors and then compare these four values to determine which values are the highest and then directs one of the Motors either horizontally or vertically to move the solar panels to the location where the highest value was detected in order to absorb the largest Quantity of solar energy.

\section{MICROCONTROLLER UNIT}

Control Circuit: An Arduino UNO R3, as shown in Figure 4, with ATmega 328 was used as a controller for the system. The idea is that Arduino will receive data from four different Light Dependent Resistor (LDR) and compare between these numbers. According to the comparison results, the controller will send signals out from pins toward the relays. These instructions control the relays by putting them in ON or OFF mode.

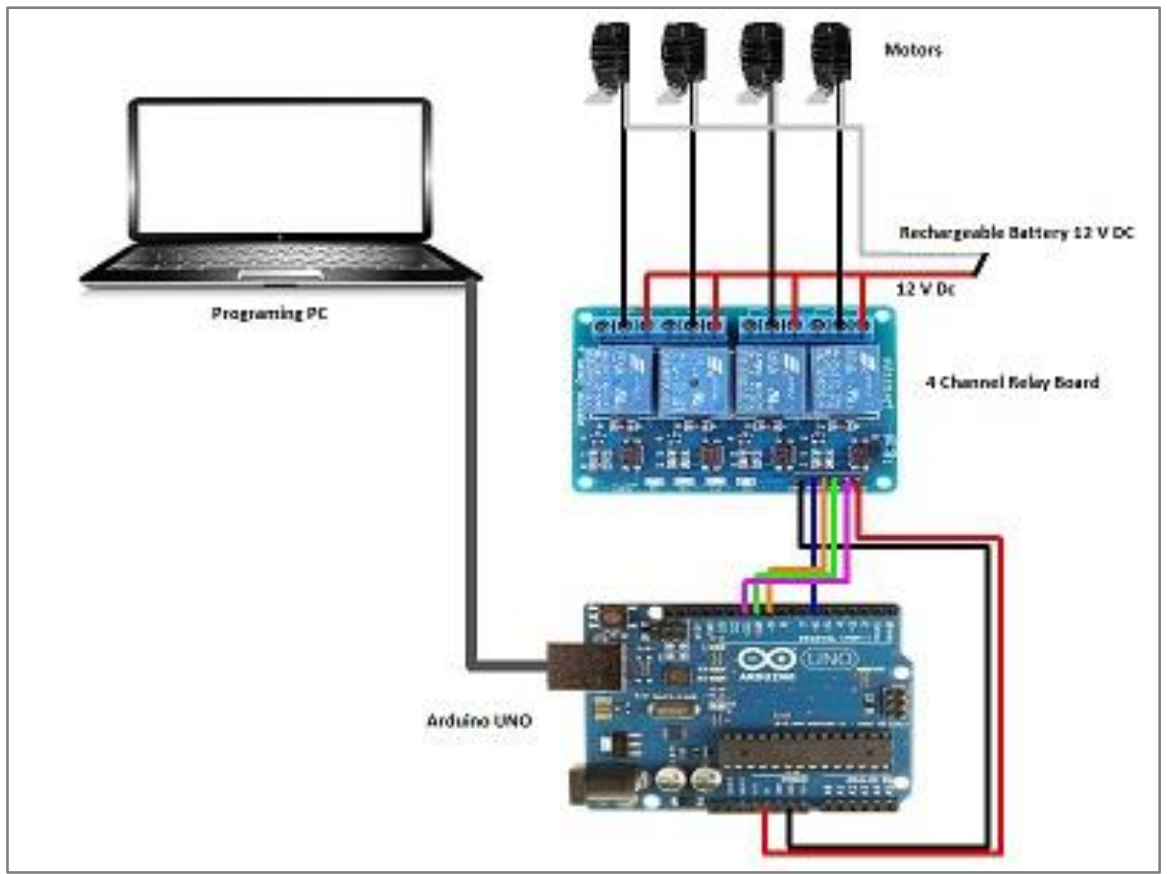

Figure 4. Arduino uno R3 and SRD-05 VDC relays 
A kit of four relays (SRD-05 VDC) was used as gates to pass the suitable voltage (12 V DC) to the motors. First two relays are used to power on the motor in a clockwise direction. Whereas the third and fourth relays are used to power the same motor in the reverse direction (counterclockwise). Four LDR sensors were used to sensing sun irradiance and send this data to Arduino. 12V DC rechargeable battery to power the motor. Different types of wires have been used for system connections.

\section{MOTOR UNIT}

Dual polarity motors have been used to control the movement of the system. Each motor is a $12 \mathrm{~V}$ Dc (Super Jack Motor) as illustrated in Figure 5, which is two directions motor clockwise and counterclockwise depending on its polarity. The polarity will control the direction of the motors and by reversing it we will get the reverse direction. The range of these types of motors is 150 degree which is suitable for the tracking systems.
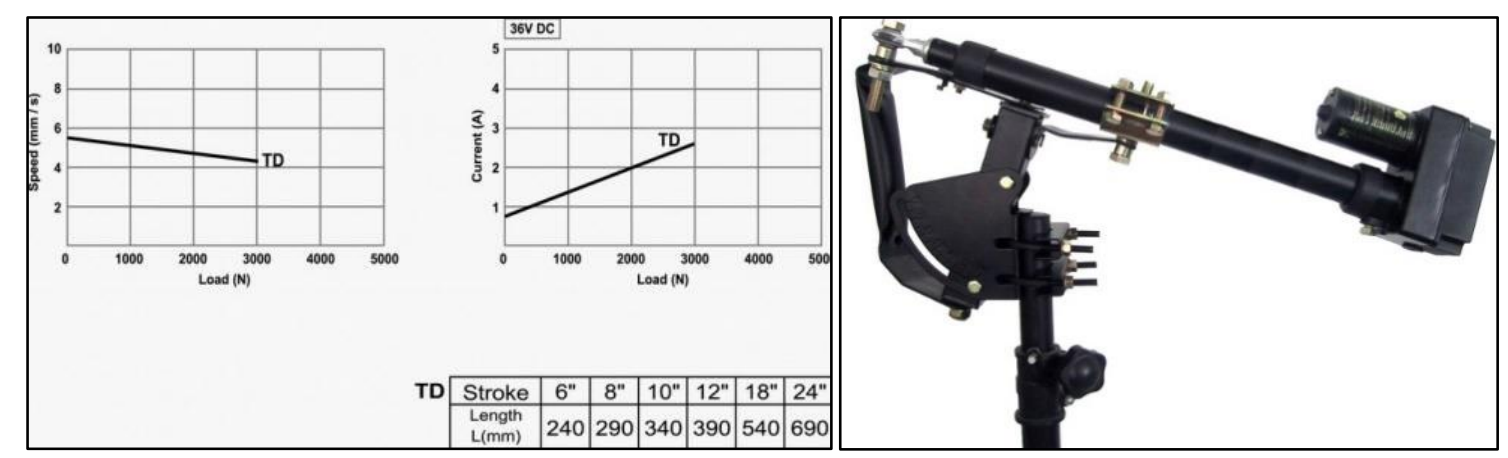

Figure 5. Super jack DC motor

\section{POWER COLLECTING UNIT}

Solar Panel: Kyocera (Japan) solar panel of 54Watt maximum power has been used in the system. It has open-circuit voltage (Voc) of 21.7V, and Short Circuit Current (Isc) of 3.13A. Table 4 shows the specification of the panel.

Table 4. Kyocera solar panel specification

\begin{tabular}{lc}
\hline \multicolumn{2}{c}{ Electrical Performance under Standard Test Conditions $(* \mathrm{STC})$} \\
\hline Maximum Power (Pmax) & $54 \mathrm{~W}(+10 \% /-5 \%)$ \\
Maximum Power Voltage (Vmpp) & $17.4 \mathrm{~V}$ \\
Maximum Power Current (Impp) & $3.11 \mathrm{~A}$ \\
Open Circuit Voltage (Voc) & $21.7 \mathrm{~V}$ \\
Short Circuit Current (Isc) & $3.31 \mathrm{~A}$ \\
Max System Voltage & $600 \mathrm{~V}$ \\
Temperature Coefficient of Voc & $-8.21 \times 10^{-2} \mathrm{~V} /{ }^{\circ} \mathrm{C}$ \\
Temperature Coefficient of Isc & $1.33 \times 10^{-3} \mathrm{~A} /{ }^{\circ} \mathrm{C}$ \\
$*$ STC : Irradiance $1000 \mathrm{~W} / \mathrm{m} 2$, AM1.5 spectrum, module temperature $25^{\circ} \mathrm{C}$ \\
\hline
\end{tabular}

\section{PROGRAM CODING}

An Arduino IDE software is used for the programming part. A complete program is written in a way that implements the sequence of the flowchart as in Figure 6. Firstly, the parameters need to be set. Pins (2 to 5) is set to control the first relays kit which is used to control the motor of the horizontal direction. Where first and second relays are run the motor in CW direction, third and fourth relays run the motor in CCW direction. The same principle will be repeated for the second kit which is used for vertical motor. The system will check the LDRs measurement every 15 minutes and move the panel toward the higher irradiance position. All the system will go in sleep mode for 8 hours (for power saving) after reaching the night threshold value of all LDRs. The night or dark threshold value has been calculated experimentally after the sunset by 15 minutes in Ramadi City. 


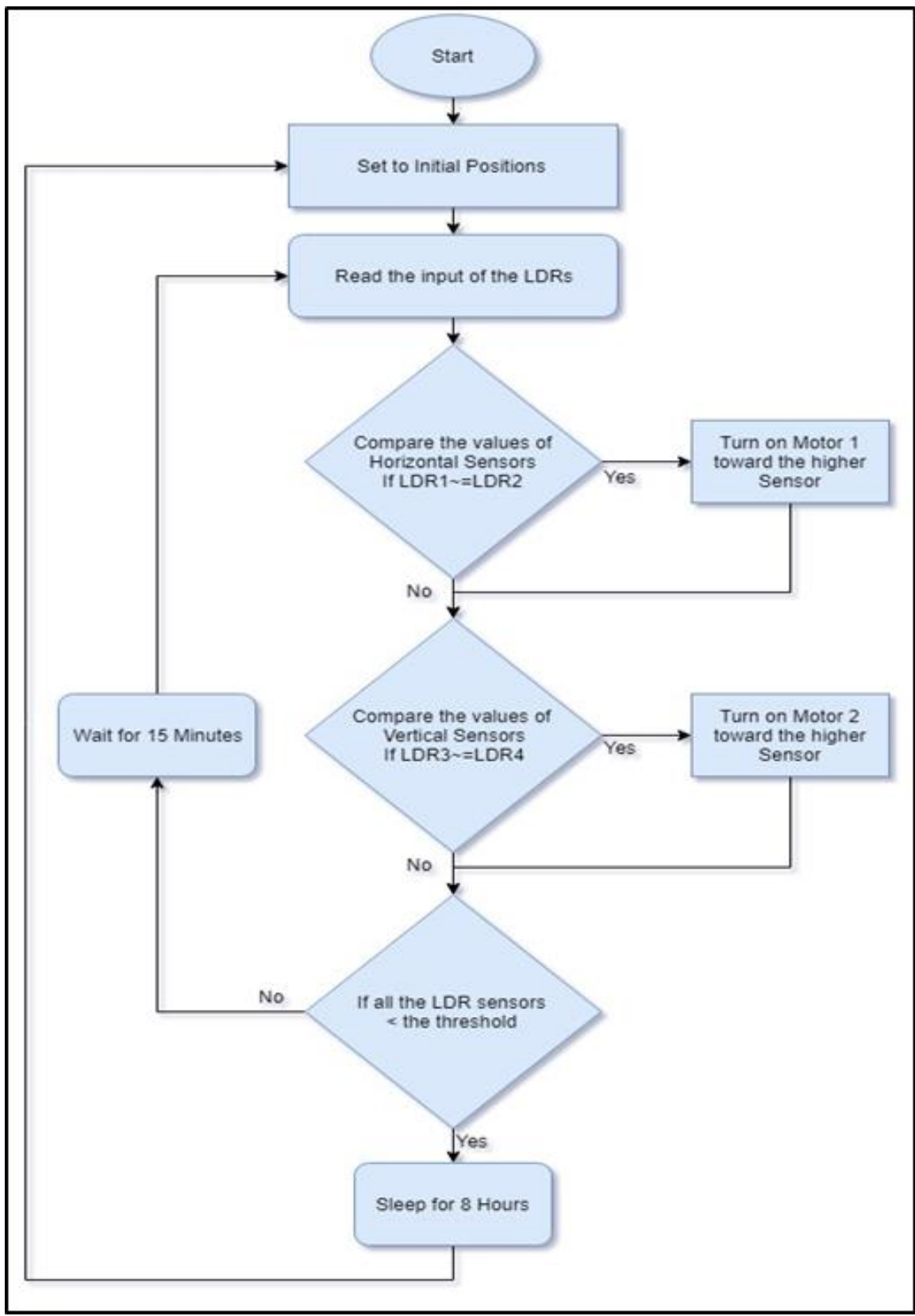

Figure 6. Flowchart of the automatic solar tracker

\section{EXPERIMENTAL}

Multi-axis iron frames have been designed as part of the project. The frame allows the panel to move in different directions. Mainly in the X-axis and the Y-axis movement. Figure 7 shows the detailed design of the tracker frame. A static panel has been mounted at 33 degrees with the horizon toward the south which are the best angle and direction for the static panels to be installed in Ramadi City. The readings are taken during a sunny day in July which has the best irradiance among all the year moths. The readings (voltage and current) are recorded hourly for thirteen hours using precise Ammeter and Voltmeter. Four different cases have been considered in the experimental part of this study, tracker with load, tracker with no load, static with load, and static with no load. The tracker system was following the Sun location successfully and gives better output than the static panel at all-day hours. The power is calculated for each system separately, yet at the same time, for comparison issue. The results are calculated using Microsoft Excel and the graphs are plotted using MATLAB. These programs helped in getting precise line graphs and precise results. 


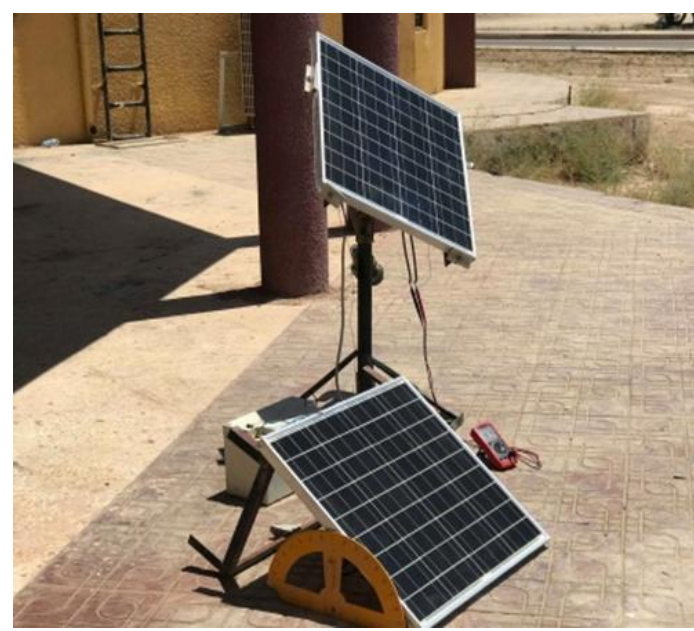

Figure 7. Multi-axis solar tracker and static solar penal

\section{RESULTS AND DISCUSSION}

At this point all parts of the system become ready for use, in other words, all the parts have been tested and combined as one system that can be work as a stand-alone system. Different results are collected in this study and compared to the results of the traditional system (fixed panel). The readings of the system have been done hourly in July 2019, at Ramadi City on a sunny day. Three types of results were taken into consideration in terms of current, voltage, and power. In addition, the average power of both systems has been compared to in two cases with the load on the system and without load. Table 5 shows the results of the solar tracking system and the fixed panel system with a load (a DC Fan). It is obvious from this table that the tracked panel output surpasses the static one with about 12 Watt per hour as average output power. Figure 8(a) shows the line graph of the obtained power for both systems in the time period from 5 o'clock to 18 o'clock on a sunny day. The upper line (the red one) represents the output power of the tracked solar panel and the lower line (the blue one) represents the output power of the fixed panel. It is clear from both table and graph that the introduced system is highly efficient than the traditional one.

Table 6 shows the results of the solar tracking system and the fixed panel system with no load. It is clear from this table that the panel output of the tracker system overcome the static one with more than 12 Watt per hour as average output power. Figure 8(b) shows the line graph of the obtained power for both systems in the time period of 13 hours from 5 o'clock to 18 o'clock on a sunny day at Ramadi City. The upper line (the red one) represents the output power of the tracked solar panel and the lower line (the blue one) represents the output power of the fixed panel. It is obvious from both table and graph that the introduced system is highly efficient than the traditional one.

Table 5. Results of the solar tracker and fixed panel with load

\begin{tabular}{ccccccc}
\hline & \multicolumn{3}{c}{ Tracker with load } & \multicolumn{3}{c}{ Fixed with load } \\
Hour & $\mathrm{A}$ & $\mathrm{V}$ & Power & $\mathrm{A}$ & $\mathrm{V}$ & Power \\
\hline 5 & 1.8 & 18.11 & 32.598 & 0.8 & 17.86 & 14.288 \\
6 & 2.23 & 19.3 & 43.039 & 1.1 & 18.43 & 20.273 \\
7 & 2.51 & 19.68 & 49.397 & 1.9 & 18.9 & 35.91 \\
8 & 2.74 & 20.02 & 54.855 & 2.12 & 19.5 & 41.34 \\
9 & 2.86 & 21.05 & 60.203 & 2.2 & 19.9 & 43.78 \\
10 & 2.96 & 20.9 & 61.864 & 2.8 & 20.3 & 56.84 \\
11 & 3 & 20.4 & 61.2 & 3 & 20.43 & 61.29 \\
12 & 3.01 & 20.34 & 61.223 & 2.9 & 20.4 & 59.421 \\
13 & 2.92 & 20.1 & 58.692 & 2.87 & 20.1 & 57.687 \\
14 & 2.9 & 18.88 & 54.752 & 2.31 & 19.8 & 45.738 \\
15 & 2.86 & 18.35 & 52.481 & 2.1 & 19.1 & 40.11 \\
16 & 2.71 & 15.01 & 40.677 & 1.7 & 14.6 & 24.82 \\
17 & 2.01 & 10.1 & 20.301 & 0.06 & 8.69 & 0.5214 \\
18 & 1.89 & 9.2 & 17.388 & 0 & 0 & 0 \\
\multicolumn{3}{c}{ Average Power } & 47.762 & & & 35.858 \\
\hline
\end{tabular}

Table 6. Results of Solar Tracker and Fixed Panel with no load

\begin{tabular}{ccccccc}
\hline & \multicolumn{3}{c}{ Tracker with no load } & \multicolumn{3}{c}{ Fixed with no load } \\
Hour & $\mathrm{A}$ & $\mathrm{V}$ & Power & $\mathrm{A}$ & $\mathrm{V}$ & Power \\
\hline 5 & 2.1 & 19.3 & 40.53 & 0.8 & 18 & 14.4 \\
6 & 2.23 & 20.94 & 46.696 & 1.1 & 18.65 & 20.515 \\
7 & 2.68 & 20.63 & 55.2884 & 1.9 & 19.8 & 37.62 \\
8 & 2.87 & 20.94 & 60.098 & 2.12 & 20.04 & 42.485 \\
9 & 2.95 & 21.34 & 62.953 & 2.2 & 21.01 & 46.22 \\
10 & 3.1 & 21.98 & 68.14 & 2.8 & 21.75 & 60.9 \\
11 & 3.14 & 22 & 69.08 & 3 & 21.6 & 64.8 \\
12 & 3.15 & 22.01 & 69.332 & 2. & 20.45 & 59.305 \\
13 & 3.09 & 22.2 & 68.598 & 2.87 & 20.35 & 58.4045 \\
14 & 2.91 & 21.21 & 61.7211 & 2.31 & 20.2 & 46.662 \\
15 & 2.86 & 21 & 60.06 & 2.1 & 19.6 & 41.16 \\
16 & 2.51 & 19.35 & 48.5685 & 1.7 & 6.5 & 28.05 \\
17 & 1.81 & 18.01 & 32.598 & 0.06 & 9.78 & 0.5868 \\
18 & 1.62 & 16.02 & 25.952 & 0 & 0 & 0 \\
\multicolumn{3}{c}{ Average Power } & 49.086 & & & 37.222 \\
\hline
\end{tabular}




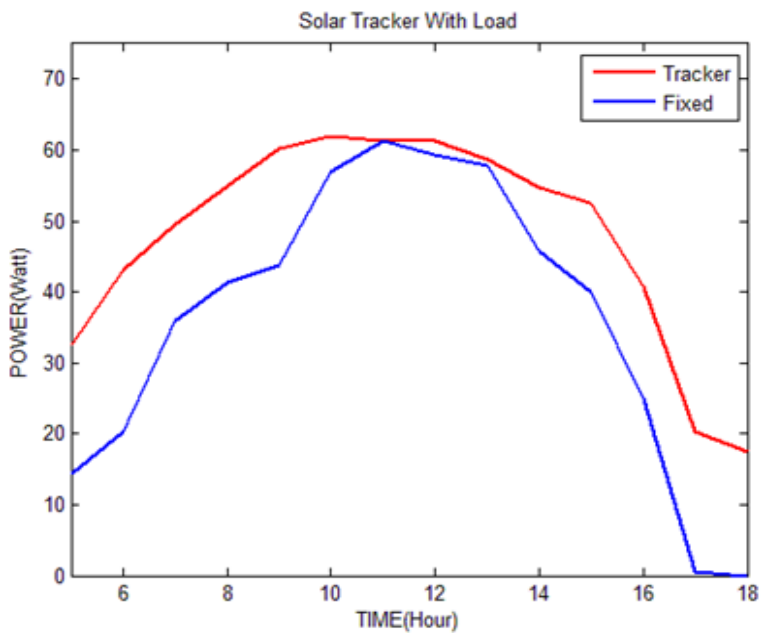

(a)

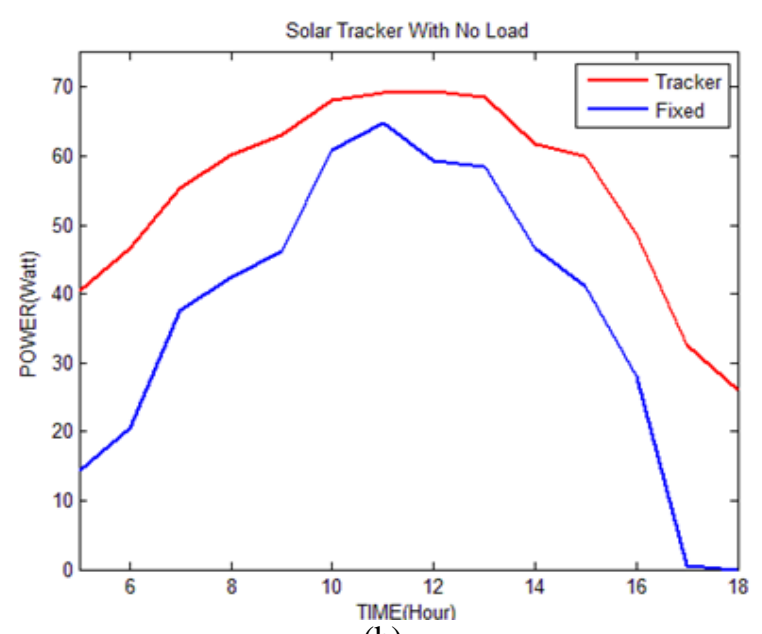

(b)

Figure 8. (a) The line graph of the output power per hour for solar tracker and fixed panel with a load,

(b) The line graph of the output power per hour for solar tracker and fixed panel with no load

\section{SYSTEM EFFICIENCY MEASUREMENT}

A comparison between the generated power of the two systems has been measured to calculate the efficiency, which is the percentage ratio of the output power to the input power. The reference for measuring the efficiency in this study is the power generated by the solar tracker. The efficiency can be expressed mathematically as:

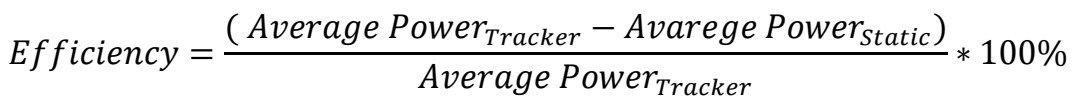

The efficiency of the system with load:

$$
\text { Efficiency }=\frac{(47.762-35.858)}{47.762} * 100 \%
$$

\section{Efficiency $=24.92 \%$}

The efficiency of the system with no load:

$$
\begin{aligned}
& \text { Efficiency }=\frac{(49.086-37.222)}{49.086} * 100 \% \\
& \text { Efficiency }=\mathbf{2 4 . 1 6 \%}
\end{aligned}
$$

\section{CONCLUSION}

An automatic multi-axis solar tracking system has been presented in this article which is allow the solar panel to be aligned directly to the Sun as long as the Sun in the sky. This tracker enables the renewable energy system of obtaining the maximum power of the solar energy. These advantages make such systems surpass the traditional systems in terms of efficiency and power gaining. The automatic tracker is built and operated successfully. The overall system is efficient, low cost, and operates automatically.

\section{ACKNOWLEDGEMENTS}

This research is supported and revised by the Scientific Committee in the Renewable Energy Research Center at the University of Anbar. 


\section{REFERENCES}

[1] C. Hua and C. Shen, “Comparative study of peak power tracking techniques for solar storage system," in $A P E C$ ' 98 Thirteenth Annual Applied Power Electronics Conference and Exposition, vol. 2, pp. 679-685, 1998.

[2] M. D. Archer and R. Hill, "Clean electricity from photovoltaics," London, Imperial College Press, vol. 1, 2001.

[3] A. K. Saxena and V. Dutta, "A versatile microprocessor based controller for solar tracking," in IEEE Conference on Photovoltaic Specialists, vol. 2, pp. 1105-1109, 1990.

[4] A. Ramizy, et al., "Good Optical Quality InxGa1-xN Thin Films Grown on Si(111) by Plasma-Assisted Molecular Beam Epitaxy,” Journal of Non-Oxide Glasses, vol. 10, no. 2, pp. 43-48, 2018.

[5] B. Koyuncu and K. Balasubramanian, "A microprocessor controlled automatic sun tracker," IEEE Trans. Consum. Electron, vol. 37, no. 4, pp. 913-917, 1991.

[6] O. Bingöl, et al., "Microcontroller Based Solar-Tracking System and Its Implementation," Journal of Engineering Sciences, vol. 12, no. 2, pp. 243-248, 2006.

[7] M. H. Al-Jumaili, et al., "Analysis of the hard and soft shading impact on photovoltaic module performance using solar module tester," International Journal of Power Electronics and Drive System, vol. 10, no. 2, pp. 1014-1021, 2019.

[8] M. F. Khan and R. L. Ali, "Automatic Sun Tracking System (ASTS)," Faculty of Electronics Engineering, Air University Islamabad, Pakistan, pp. 1-4, 2005.

[9] J. Wu, et al., "Design and Dynamics of a Novel Solar Tracker with Parallel Mechanism," IEEE/ASME Transactions on Mechatronics, vol. 21, no. 1, pp. 88-97, 2016.

[10] E. H. Sabbar, et al., "Fabricated Solar Cell from ZnO/a-Si/Polymers," International Journal of Advanced Science and Technology, vol. 44, pp. 89-98, 2012.

[11] J. Kartite and M. Cherkaoui, "Improved backtracking search optimization algorithm for PV/Wind/FC system," TELKOMNIKA Telecommunication, Computing, Electronics and Control, vol. 18, no. 1, pp. 456-464, 2020.

[12] R. ur Rahman, et al., "Performance enhancement of PV solar system by diffused reflection," in 2009 1st International Conference on the Developements in Renewable Energy Technology (ICDRET), pp. 1-4, 2009.

[13] N. A. Shalash and Y. N. Lafta, "PSS/E based placement wind/PV hybrid system to improve stability of Iraqi grid," International Journal of Electrical and Computer Engineering (IJECE), vol. 10, no. 1, pp. 91-104, 2020.

[14] Suncurves.com, "Accurate sunrise and sunsite times for any location worldwide: Sunrise and sunset times> Ramadi, Iraq,” 2019. Available: http://suncurves.com/en/v/15160/.

[15] M. Al-Jumaili and B. Karimi, "Maximum bottleneck energy routing (MBER) - An energy efficient routing method for wireless sensor networks," in 2016 IEEE Conference on Wireless Sensors (ICWiSE), pp. 38-44, 2016.

[16] I. S. Madugu, et al., "A novel model for solar radiation prediction," TELKOMNIKA Telecommunication, Computing, Electronics and Control, vol. 17, no. 6, pp. 3100-3109, 2019.

[17] N. Al-Rousan, et al., "Advances in solar photovoltaic tracking systems: A review," Renewable and Sustainable Energy Reviews, vol. 82, no. 3, pp. 2548-2569, 2018.

[18] B. Mohammed, et al., "Design and modeling of optical reflectors for a PV panel adapted by MPPT control," Indonesian Journal of Electrical Engineering and Computer Science, vol. 16, no. 2, pp. 653-660, 2019.

[19] A. P. Aigboviosa, et al., "Arduino Based Solar Tracking System for Energy Improvement of Pv Solar Panel," International Conference on Industrial Engineering and Operations Management, pp. 2469-2478, 2018.

[20] H. Mousazadeh, et al., "A review of principle and sun-tracking methods for maximizing solar systems output," Renewable and Sustainable Energy Reviews, vol. 13, no. 8, pp. 1800-1818, 2009.

[21] N. H. A. Rahman, et al., "Design and development of three stages maximum power tracking solar charge controller," Indonesian Journal of Electrical Engineering and Computer Science, vol. 18, no. 3, pp. 1270-1278, 2020.

[22] M. J. Fadhil, et al., "Design and implementation of smart electronic solar tracker based on Arduino," TELKOMNIKA Telecommunication Computing Electronics and Control, vol. 17, no. 5, pp. 2486-2496, 2019.

[23] B. Parida, et al., "A review of solar photovoltaic technologies," Renewable and Sustainable Energy Reviews, vol. 15, no. 3, pp. 1625-1636, 2011.

[24] M. Z. M. Nasir, et al., "Prototype development of smart parking system powered by solar photovoltaic," Indonesian Journal of Electrical Engineering and Computer Science, vol. 18, no. 3, pp. 1229-1235, 2020.

[25] N. Rawat, et al., "Solar PV parameter estimation using multi-objective optimization," Bulletin of Electrical Engineering and Informatics, vol. 8, no. 4, pp. 1198-1205, 2019. 